\title{
A rare case of spontaneous hepaticoduodenal fistula and management of biliary obstruction in metastatic cholangiocarcinoma
}

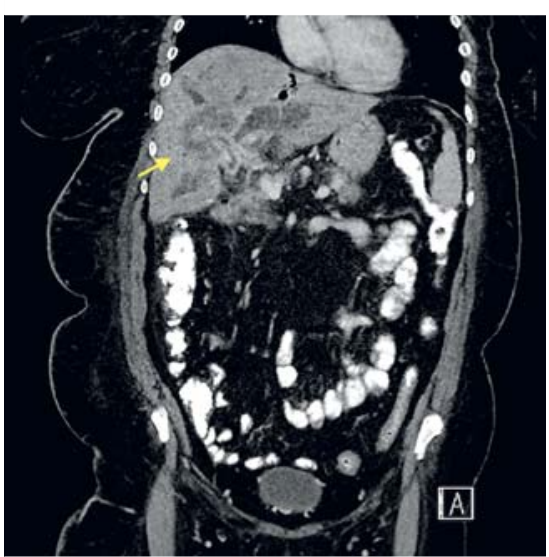

- Fig. 1 Computed tomography scan of the abdomen/pelvis (coronal view) demonstrating a large hilar liver mass with intrahepatic biliary dilatation (arrow).

A 60-year-old woman with a history of breast cancer presented with jaundice, epigastric pain, and fever for 1 week. Laboratory results revealed a total bilirubin of $14.9 \mathrm{mg} / \mathrm{dL}$ and alkaline phosphatase of $365 \mathrm{U} / \mathrm{L}$. Abdominal computed tomography revealed a $6.1 \times 2.8-\mathrm{cm}$ hilar liver mass with intrahepatic biliary dilatation ( Fig. 1; V Video 1); subsequent abdominal magnetic resonance imaging demonstrated an infiltrative soft tissue mass encasing the common hepatic and central intrahepatic ducts, suggestive of intrahepatic cholangiocarcinoma ( $\triangleright$ Fig. 2).

Endoscopic ultrasound (EUS) demonstrated a fistulous tract, which was draining into the duodenal bulb ( $\triangleright$ Video 1 ). EUS-guided fine needle aspiration (FNA) of the liver mass was performed. During endoscopic retrograde cholangiopancreatography (ERCP), despite cannulation of the major papilla, the guidewire could not be advanced to the proximal common hepatic duct; a cholangiogram revealed complete obstruction of the proximal common bile duct ( $>$ Fig.3). Contrast injection through the fistulous tract in the duodenal bulb confirmed a

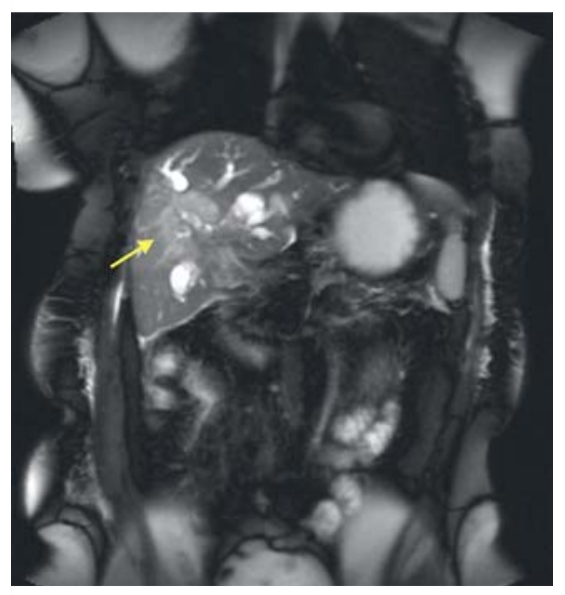

- Fig. 2 Magnetic resonance imaging of the abdomen/pelvis (T2-weighted, coronal view) demonstrating a hilar liver mass with marked intrahepatic biliary dilatation (arrow).

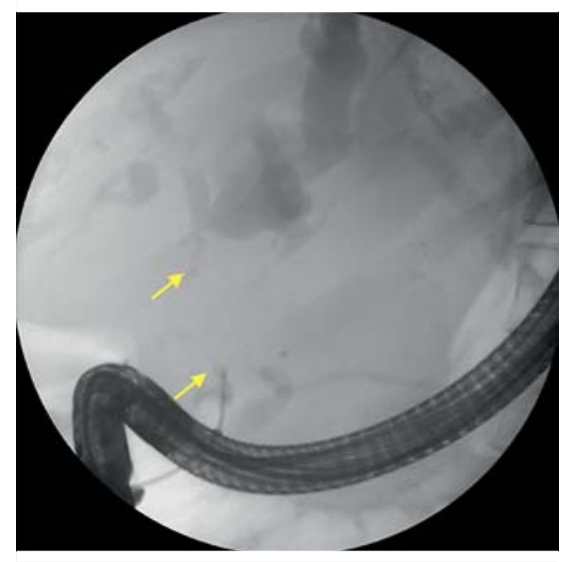

- Fig. 3 Cholangiogram demonstrating complete obstruction of the proximal common bile duct (arrows).

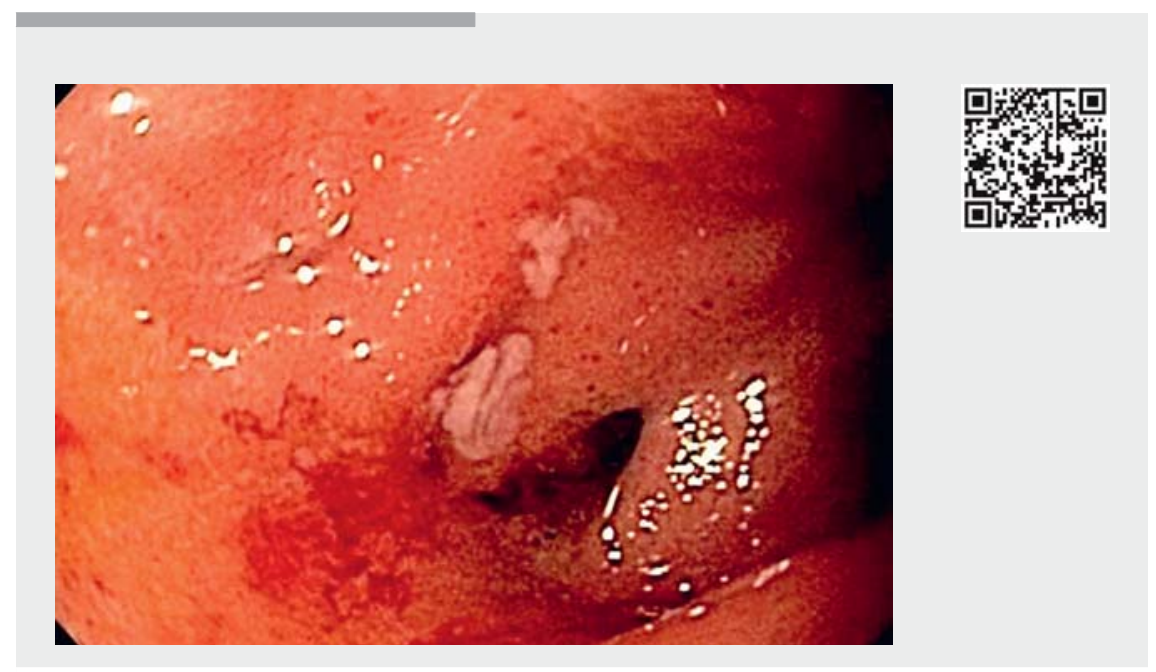

$\checkmark$ Video 1 A spontaneous hepaticoduodenal fistula is found in a patient with cholangiocarcinoma; plastic stents, and later a covered metal stent, are placed to drain the dilated intrahepatic ducts.

hepaticoduodenal fistula with marked intrahepatic duct dilatation. The fistula tract was dilated and two plastic biliary stents were placed with their proximal ends in the right and left main hepatic ducts and good flow resulted ( $\triangleright$ Fig. 4 and $>$ Fig. 5 a).
After 2 weeks, the patient's liver enzymes had notably improved and the plastic stents were exchanged for a covered metal stent ( $\triangleright$ Fig. $\mathbf{5}$ b and $\triangleright$ Fig. $\mathbf{6}$ ). Pathology from the EUS-FNA demonstrated adenocarcinoma morphologically favoring a cholangiocarcinoma, and 


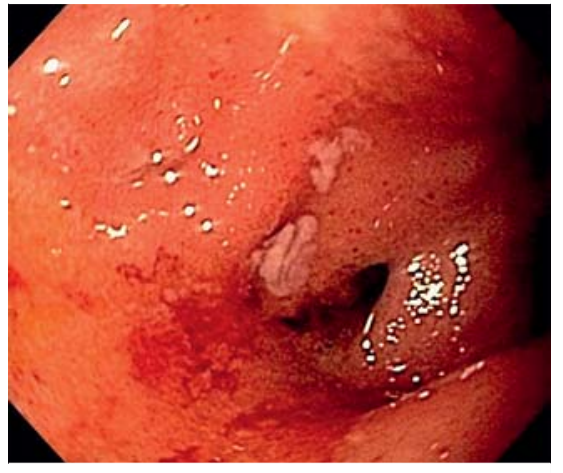

- Fig. 4 Endoscopic view showing a fistulous tract opening in the duodenal bulb.

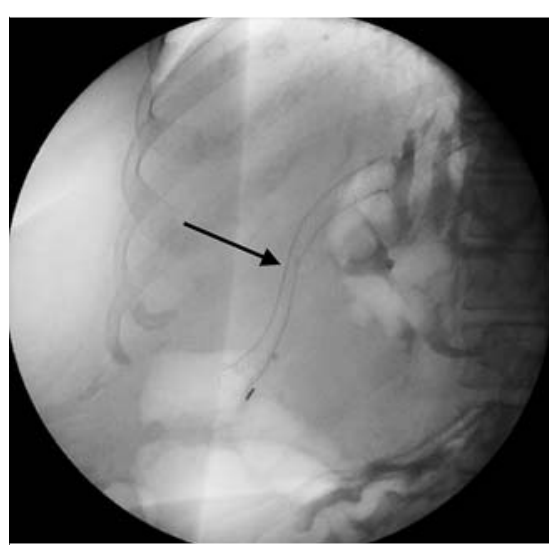

- Fig. 6 Cholangiogram showing the covered metal stent in position (arrow).

the patient was referred to medical oncology.

Hepaticoduodenal fistulas are generally iatrogenic complications, occurring after transcatheter arterial chemoembolization or surgery complicated by bile duct injury $[1,2]$. There are very few reports of biliary compression with stent placement utilizing identified hepaticoduodenal fistulas $[3,4]$. EUS-guided choledochoduodenostomy is an emerging technique for biliary decompression when routine ERCP techniques are unsuccessful [5]. To our knowledge and from a review of the literature, this is the first reported case of a spontaneous hepaticoduodenal fistula that was utilized to facilitate palliative and therapeutic biliary decompression.

Endoscopy_UCTN_Code_TTT_1AR_2AF
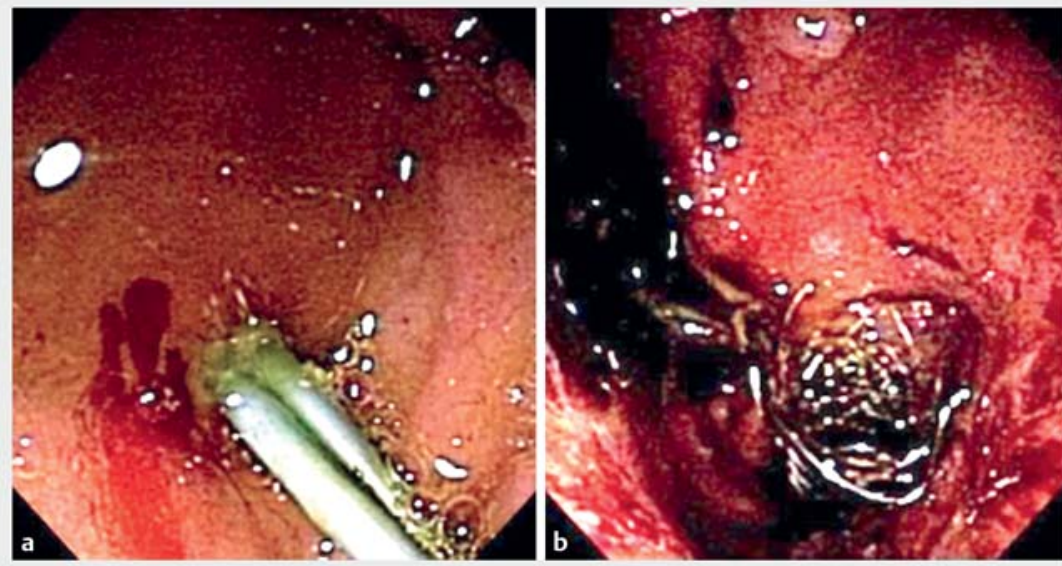

- Fig. 5 Endoscopic views showing: a a hepaticoduodenal fistula with plastic biliary stents in place; $\mathbf{b}$ a hepaticoduodenal fistula after a covered metal stent had been exchanged for the plastic stents.

\section{Competing interests}

None

The authors

Andrew J. Kruger ${ }^{1}$, Somashekar G. Krishna ${ }^{2}$

1 Department of Internal Medicine, The Ohio State University Wexner Medical Center, Columbus, Ohio, USA

2 Divisions of Gastroenterology, Hepatology and Nutrition, The Ohio State University Wexner Medical Center, Columbus, Ohio, USA

\section{Corresponding author}

\section{Somashekar G. Krishna, MD, MPH}

395 W 12th Ave, 2nd Floor, Columbus,

$\mathrm{OH} 43210$, USA

Fax: +1-614-293-8518

somashekar.krishna@osumc.edu

\section{References}

[1] Prachayakul V, Aswakul P. Spontaneous hepaticoduodenal and choledochoduodenal fistula mimicking duodenal ulcer perforation, a very rare complication of transarterial chemoembolization. Case Rep Gastroenterol 2015; 9: 68-73

[2] Ozoğul YB, Ozer I, Oruğ T et al. Spontaneous hepaticoduodenal fistula functioning like a bilioenteric anastomosis following bile duct injury: case report. Turk J Gastroenterol 2009; 20: $220-223$
[3] Hoevels ], Lunderquist A, Ihse I. Percutaneous transhepatic intubation of bile ducts for combined internal-external drainage in preoperative and palliative treatment of obstructive jaundice. Gastrointest Radiol 1978; 3: $23-31$

[4] Baijal SS, Roy S, Choudhuri G. Extra-anatomic stenting of the biliary system. Indian ] Gastroenterol 1993; 12: $58-59$

[5] Yamao K, Bhatia V, Mizuno N et al. EUS-guided choledochoduodenostomy for palliative biliary drainage in patients with malignant biliary obstruction: results of long-term follow-up. Endoscopy 2008; 40: 340 - 342

\section{Bibliography}

DOI https://doi.org/10.1055/a-0628-6172

Published online: 19.6.2018

Endoscopy 2018; 50: E242-E243

(c) Georg Thieme Verlag KG

Stuttgart · New York

ISSN 0013-726X

\section{ENDOSCOPY E-VIDEOS}

https://eref.thieme.de/e-videos

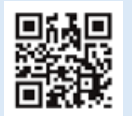

Endoscopy E-Videos is a free access online section, reporting on interesting cases and new techniques in gastroenterological endoscopy. All papers include a high quality video and all contributions are freely accessible online.

This section has its own submission website at

https://mc.manuscriptcentral.com/e-videos 